\section{Misguided thinking on animals}

SIR-Clive Hollands' chastisement (Nature 339, 248; 1989) of Nature for its publication of work involving two monkeys (Nature 337, 265-267; 1989) should certainly be a cause of great concern to scientists in Britain - not because of his specific criticism of the research (which is the usual list of lurid surgical details without a word about anaesthetics or scientific objectives) but because Hollands speaks with apparent authority about the British law. When he tells us that Nature has sinned by publishing work "which clearly would not have been authorized under British law", this is not just the wishful thinking of someone who would like to see an end to all medical research involving animals; for Hollands is a member of the Animal Procedures Committee, which advises the Home Secretary about the balance between "the legitimate requirements of science" and "the protection of animals against avoidable suffering". We who work under the strict British law had assumed that applications to perform research are considered on their merits, taking due account of the quality and importance of the science involved. Either Hollands believes that the Animals (Scientific Procedures) Act 1986 bans certain techniques perse, or he thinks that a single member of a large committee is entitled to pronounce in advance on what would not be acceptable. In my opinion, both assumptions are wrong and I trust that others will join me in asking the Home Secretary to comment on the right of a member of this important committee to pontificate in this way.

The research that Hollands parodies in his letter addresses fundamentally important questions about the mechanisms of development of the cerebral cortex. It was performed skilfully and humanely in one of the leading centres for biomedical research in France, which works on AIDS, Alzheimer's disease and rehabilitation after brain damage, as well as on fundamental neuroscience. I have collaborated with scientists there for many years in a study of the causes of childhood blindness and have found the animal house and laboratory facilities, as well as the quality of research, among the best that I have seen anywhere.

On 21 May, 'animal rights' terrorists broke into that very institute and stole almost 100 animals. Among them were 38 monkeys, including social family groups that had been established for nearly a decade and animals that were born in the laboratory and had never experienced any other environment. Perhaps Hollands would like to give us his opinion of the cruelty and stress involved in their forced removal and would tell us whether such treatment, without any scientific objective at all, would be permitted under British law. I share the anger of my French colleagues at such wanton torture of animals in the name of their protection, as well as grief at the setback by years to important research.

Medical research is fighting for its survival against an upsurge of 'animal rights' activity. The response of the scientific community in the United States has been rapid and is increasingly effective. Animal rights protesters are now met with counter-demonstrations organized by medical interest groups and charities. Thirty-two Nobel laureates have recently written to the US Surgeon General urging him to warn the American public of the danger posed by the animal rights movement to legitimate and urgent biomedical research. We in Europe must also recognize the threat that we face and mobilize to resist the philistine forces that would stop the progress of medicine - from Hollands' pronouncements about his personal law to the stupidity of theft of animals and bombing of universities.

COLIN BLAKEMORE

University Laboratory of Physiology,

Parks Road, Oxford OX1 3PT, UK

\section{Peer review}

SIR-As editor of a national physics journal, I am sympathetic to many of the comments made by other contributors to the discussion on anonymous peer reviewing. But, for the best good of science, the first priority has to be the maintenance of high-quality well-regarded international research journals which appear regularly.

Publication of one's work (which is closely coupled to one's ego - and one's research grants) is not a democratic right; it is a privilege. The suitability of the work for publication is based on the opinion of peers, both referees and journal editors, who act as arbiters of conflicting opinions.

From a pragmatic point of view, the timely operation of science journals depends to a large extent on the willing provision of a free refereeing service, provided on invitation, by the large cadre of referees that each journal recruits. By definition, these people are also busy and productive researchers who would prefer to be doing and writing science. But they are willing to give generously, at no cost except to themselves, of their precious creative time, to read and comment on typescripts sent to them. They do this as part of their citizens' duties to the republic of science.

Human nature being what it is, I very much doubt if journal editors could easily find referees to provide this service so willingly if it were not on the implicit understanding of anonymity. Some referees, myself included, often sign their refereeing comments, but that is as much a personal decision as that of the author in sending the paper to a particular journal for consideration for publication.

Authors, referees and editors all have their human foibles which are sometimes revealed in the anonymous referee reports. But my experience in the past few years of editing a physics journal has convinced me that only a very small minority of referees misuse anonymity to make unwarranted and discourteous remarks. Such behaviour calls for an editorial judgement on the quality of the referee's report, and the prompt securing of alternative independent assessments by others. Most of the many referees' comments that I have read relating to the few hundred papers we handle each year are helpful, supportive and often include extensive valuable suggestions for significant improvements to the quality of the papers. These comments are nearly always appreciated by the authors. An author's reputation depends on the quality of the material that actually gets into print. It can only be enhanced by supportive and helpful refereeing suggestions.

RALPH W. NiCHOLLS Editor, Canadian Journal of Physics, York University, North York, Ontario, Canada M3J $1 P 3$

SIR-Your leader on peer review (Nature 339, 11; 1989) interests me greatly, because I do not know just how peers are chosen these days. In particular, although those who are concerned with fields contiguous to the work described may be able to read papers referred to them without difficulty, their very proximity to the matter may on occasion prove to be a disadvantage.

The current plethora of publications is the inevitable consequence of the view in academic circles that one's status is a function of the number of one's personal publications. This has changed the academic purpose from that of ascertaining natural laws to the aggrandisment of individuals: once the individual becomes more important than the community in which he lives and works, the end of that community is in sight.

Incidentally, the 'black-balling' system still operates. At least one technical society I know allows membership by invitation only: a friend of mine who had to move to a different part of this country and was concerned to get to know local people enquired of the local branch of a famous international body about joining it, and was told to wait until he was asked. Whether one would wish to join anything which behaved in this way, is a question that borders on the moot.

89 Apton Road, Bishop's Stortford, Hertfordshire CM23 3ST, UK 